\title{
ESTUDO SOBRE OS RESULTADOS DA IRRIGAÇÃO EM COLOSTOMIZADOS SUBMETIDOS A UM PROCESSO DE TREINAMENTO SISTEMATIZADO*
}

\author{
Vera Lucia Conceigäo de G. Santos** \\ Maria Sumie Koizumi***
}

SANTOS, V.L. C. de G.; KOIZUMI, M. S. Estudo sobre os resultados da irrigaçáo em colosto- mizados submetidos a um processo de treinamento sistematizado. Rev. Esc. Enf. USP., v. 26, n. 3, p. - , dez., 1992.

O presente estudo versa sobre os resultados do emprego da auto-irrigação por 40 colostomizados, por nós treinados através de um processo de treinamento sistematizado. A efetividade do processo de treinamento pode ser constatada a medida que a maioria dos clientes o adotou em seus itens básicos, apontando pequeno número de dificuldades técnicas. Quanto aos resultados da cutoirrigação, como método de controle do habito intestinal, verificou-se que $37,50 \%$ da populaçäo apresentou ausência de perdas fecais e 42,50\%, perdas esporádicas entre as irrigaçסes; 27,50\% e $35,00 \%$ com ausência e reduçdo dos gases nesses intervalos, respectivamente e 32,50\% e 37,50\% com aboliçâo total e parcial do uso da bolsa coletora, respectivamente.

UNITERMOS: Ostomia Cuidados de colostomia Irrigação

\section{INTRODUÇÃO}

O interesse pela efetividade do processo de reabilitação do paciente portador de um estoma tem aumentado muito nos últimos anos, em todo o mundo, acarretando como conseqüência o desenvolvimento de vários estudos dirigidos especialmente para a busca de soluções para o problema da incontinência fecal.

O controle da função intestinal no colostomizado tem sido estudado por meio de métodos alternativos como o natural, a utilização de dispositivos oclusores intestinais, as operações que retardam o trânsito intestinal, o condicionamento psicofísico e a irrigação $(2,4,5,6,8,11,13,19,20,22,24,26)$.

A irrigação da colostomia é um método mecânico para o controle das eliminações intestinais. Consiste num enema realizado a cada 24,48 ou 72 horas, cujo fluido, enviado ao intestino grosso através do estoma, estimula sua peristalse em massa e assim o esvaziamento do conteúdo fecal(1, 3, 9, 12, 14, 17, 19, 27).

Esse método, como os demais, tem como finalidades básicas estabelecer um hábito intestinal regular no colostomizado, reduzir gases e odor, através da diminuição da flora bacteriana normal e, conseqüentemente, diminuir a freqüên-

- Extraldo da Monografia de Mestrado, apresentada à Escola de Enfermagem da USP.

-* Enfermeira. Estomaterapeuta. Assistente do Departamento de Enfermagem Médico-Cirárgica da EEUSP.

** Enfermeira. Prof. Doutor do Departamento de Enfermagem Médico-Cirúrgica da EEUSP. 
cia do uso de bolsas coletoras, evitando o aparecimento das lesões de pele periestoma e minimizando os custos financeiros $(1,3,12,17,18,27)$.

Todos os métodos apresentados para o tratamento do colostomizado com a finalidade de possibilitar-lhe atingir a regularização do hábito intestinal, possuem vantagens e desvantagens. No entanto, ao buscarmos um método acessível ao indivíduo pela sua simplicidade e baixo custo, que não implique em procedimentos agressivos e que não lhe impinja restrições de qualquer natureza, chegamos muitas vezes à irrigação da colostomia como uma alternativa a escolher.

O desenvolvimento do nosso trabalho na assistência a ostomizados tanto a nível domiciliar como institucional em um Serviço de Assistência existente há 5 anos, associado a um trabalho em equipe e aos nossos estudos, especificamente quanto à irrigação de colostomias, possibilitou-nos a elaboração de um plano assistencial que inclui o processo de treinamento da auto-irrigação. Mais recentemente, elaboramos um protocolo para o levantamento sistematizado dos dados específicos sobre o método da irrigação, desde o treinamento até aos resultados imediatos e tardios.

Cumpre salientarmos que a nomenclatura "auto-irrigação" não é comum entre os pesquisadores, sendo que a nossa opção em utilizá-la deve-se ao fato do processo de treinamento por nós adotado priorizar o aprendizado do cliente, embora a família também participe efetivamente. $O$ treinamento de um familiar para executar a irrigação no cliente deve restringir-se àqueles casos em que o colostomizado seja portador de deficiências físicas, mentais ou psicologicas que o impossibilite de aprender e realizar o método sozinho.

Assim, uma vez que dispúnhamos de uma clientela já treinada quanto a auto-irrigação, cujos resultados conhecíamos de forma não sistematizada e, portanto, sem uma avaliação tanto da efetividade da irrigação, como do processo de treinamento adotado e sabendo que esses fatores poderiam subsidiar o programa de reabilitação já existente em nosso serviço, além da ampliação do protocolo específico para o seguimento do cliente que se irriga, optamos pelo desenvolvimento deste estudo, tendo como objetivo: verificar os resultados da auto-irrigação alcançados pelos clientes quanto ao procedimento, eliminações de fezes e gases e uso da bolsa coletora, após um processo de treinamento sistematizadó.

\section{METODOLOGIA}

\subsection{População}

A população incluída neste estudo foi de 40 colostomizados, dos quais 34 foram atendidos em caráter particular, em domicílio e os demais eram clientes matriculados no Núcleo de Assistência a Ostomizados de um hospital-escola. Cumpre ressaltar que todos eram colostomizados, que haviam sido operados por câncer de reto e preenchiam alguns requisitos pré estabelecidos, dentre os quais terem sido treinados por nós ou por outra enfermeira pertencente a nosso Serviço. 


\subsection{Método}

Os dados foram obtidos por meio de um questionário previamente testado e enviado pelo correio.

O questionário propriamente dito, abrangeu 4 itens: dados sobre a irrigação; fatores anteriores a doença e colostomia; fatores atuais, e dados sobre os resultados da irrigação. Os itens relacionados aos fatores atuais e aos resultados da irrigação foram delimitados para o que ocorreu nos últimos 3 meses imediatamente anteriores ao recebimento do questionário pelo cliente.

Antes do envio do questionário, durante o contato telefónico realizado para a seleção dos clientes, explicamos a eles a finalidade do estudo e obtivemos a confirmação de sua participação, ratificando a importância da devolução imediata dos questionários devidamente preenchidos.

\subsubsection{Processo de treinamento para a auto-irrigaçáo}

O processo de treinamento, a que se submeteram os clientes e que consta dos critérios de seleção, era padronizado e já foi descrito por nos em recente publicação(21).

O treinamento é feito em 3 a 4 sessões, preferencialmente em 3 a 4 dias seguidos, e é sempre antecedido por um levantamento de dados acerca do autocuidado do colostomizado, de suas condições sanitárias domésticas, além de informações concernentes ao próprio método.

Na primeira sessão, após a demonstração do aparelho específico, executamos o procedimento da irrigação, explanando-o ao indivíduo, passo a passo. $\mathrm{Na}$ segunda sessão, averiguamos os resultados da primeira irrigação. $O$ cliente inicialmente relembra os passos do método, executando-o a seguir, sob nossa supervisão, quando o auxiliamos na resolução das dificuldades apresentadas. Na terceira sessão, novamente o cliente informa-nos dos resultados da segunda aplicação e relata a técnica antes de executá-la, de forma mais independente. Nesta fase, desde que o colostomizado atenda aos itens básicos do método, ele é liberado para irrigar-se sozinho em domić́lio. Caso contrário, é submetido a uma quarta sessão ou mais, se necessário.

Uma vez considerado apto a auto-irrigar-se, fornecemos ao cliente um manual de orientações específicas(10), além de enfatizarmos a importância de estabelecer um horário e ritmo para a execução do procedimento.

O procedimento de irrigação(10) é também uma das etapas do processo de treinamento e encontra-se sistematizado.

Os itens pré-estabelecidos que o cliente deve atender ao final da terceira sessão, para que possa ser considerado apto a auto-irrigar-se sem supervisão, são: - descrever os passos do procedimento da irrigação;

- identificar a altura adequada da base do irrigador em relação ao próprio ombro, na posição sentada ou em pé;

- reconhecer a temperatura adequada da água, que deve ser morna;

- retirar o ar do sistema de conexóes antes de introduzir o cone no estoma; 
- introduzir e manter o cone na colostomia de forma adequada, sem comprimila e sem permitir médios e grandes vazamentos que podem comprometer os resultados;

- infundir a água em velocidade constante, no tempo preconizado (5 a 10 minutos);

- impedir a penetração de ar no intestino, ao término da fase de infusão;

- reconhecer os principais problemas que podem ocorrer durante e após a irrigaçăo, além de suas respectivas soluções;

- descrever os cuidados de conservação e limpeza do equipamento para a irrigação.

\section{RESULTADOS E DISCUSSÄO}

Os resultados obtidos estão apresentados sob a forma de tabelas, com discussão concomitante.

A idade da população estudada variou de 36 a 84 anos, sendo predominante a faixa entre 56 e 65 anos (47,50\%). Quanto ao sexo, houve predomínio do feminino (60\%). A maioria dos colostomizados apresentavam hábito intestinal regular para fezes $(74,36 \%)$ e normal para gases $(46,15 \%)$, sendo de $43,59 \%$ aqueles com ambas características; além de $64,10 \%$ que referiram nunca apresentar diarréia quando submetidos a situações de estresse na fase pré-doença.

Verificamos ainda que $75,00 \%$ dos clientes efetuaram o treinamento para a execução da auto-irrigação até o 4 mês após o evento cirúrgico (a partir do 60 dia de pós-operatório).

Cumpre mencionar que $67,50 \%$ da população estudada não utilizava medicações, o que poderia interferir na regularidade do hábito intestinal, com o emprego da auto-irrigação.

Os resultados do emprego da auto-irrigação, obtidos pelos clientes do presente trabalho, englobaram os aspectos concernentes ao procedimento, eliminações de fezes e gases e uso da bolsa coletora.

Pelos dados que apresentamos a seguir, podemos constatar que o procedimento descrito anteriormente, foi adotado pela maioria dos clientes.

O aparelho para a execução da auto-irrigação, por nós indicado é, sem dúvida alguma, o tipo cônico convencional, pela segurança e conforto que oferece.

Quanto ao volume de água, a maioria dos clientes $(57,50 \%)$ empregava $1.000 \mathrm{ml}$, seguidos de $32,50 \%$ que utilizam entre 1.100 e $1.500 \mathrm{ml}$. Esses dados refletem nossa prática diária, onde a indicação para o volume adequado tem-se fundamentado inicialmente, no tipo biofísico e na dieta e, posteriormente, também nos resultados alcançados.

Em relação ao tempo total utilizado para a execução da irrigação observamos que $67,50 \%$ dos clientes dispendem de 40 a 60 minutos. A média obtida para o tempo total gasto no procedimento da irrigação foi de 50 minutos e 24 segundos.

Já, o tempo utilizado para a infusão da água foi de 5 a 10 minutos, para $75,00 \%$ dos clientes. 
A maior parte dos colostomizados investigados $(72,50 \%)$ executa a irrigação no período da manhã. A maior preferência pelo horário matutino, independentemente do sexo, pode corresponder ao predomínio diurno das atividades, principalmente de trabalho.

Quanto à frequência com que os clientes executam a auto-irrigação, $62,50 \%$ dos clientes a realizam diariamente e $30 \%$, em dias alternados. É importante assinalar que o indivíduo so deve alterar o intervalo de 24 horas para 48 ou 72 horas, quando alcançar as 24 horas sem evacuaçőes.

A existência de um processo de treinamento da auto-irrigação, mesmo que eficiente, năo elimina totalmente a ocorrência de dificuldades que podem interferir nos resultados obtidos. Neste estudo, a maioria dos clientes $(90,00 \%)$ não mencionou apresentar dificuldades para a auto-irrigação.

Um aspecto que deve ser lembrado, ao identificar-se as dificuldades apresentadas pelos clientes que se auto-irrigam, é a possibilidade de se discutir suas soluções. Acreditamos que o seguimento sistematizado dos clientes, feito principalmente em serviços especializados de assistência possibilita o desenvolvimento de um plano de orientações individualizado que permite auxiliá-los na resolução de seus problemas.

TABELA 1 - Número e percentagem de clientes segundo as perdas fecais nos intervalos das irrigações. São Paulo, 1988.

\begin{tabular}{l|c|c}
\hline Perdas fecais & N2 & $\%$ \\
\hline Esporadicas & 17 & 42,50 \\
Inexistentes & 15 & 37,50 \\
1 vez/dia & 4 & 10,00 \\
2 vezes/dia & 3 & 7,50 \\
Não respondeu & 1 & 2,50 \\
\hline Total & 40 & 100,00 \\
\hline
\end{tabular}

A maior parte dos clientes ou não tem perdas fecais $(37,50 \%)$ ou as apresenta esporadicamente $(42,50 \%)$ nos intervalos das irrigações (Tabela 1$)$.

Resultados semelhantes foram obtidos por diversos autores que efetuaram estudos comparativos ou não com outros métodos de controle do hábito intestinal, obtendo percentuais que variaram de 60 a $100 \%$ das populações de colostomizados, apresentando perdas fecais ausentes ou esporádicas entre as irrigações. JAO et al13 obtiveram $74 \%$ dos clientes que se irrigavam regularmente, com perdas fecais ausentes ou mínimas entre as irrigaçðes. SEARGEANT(23) constatou que dentre 165 pacientes investigados, 47 não apresentavam funcionamento da colostomia entre as irrigações, 58 tinham raro funcionamento e 23 , ocasional. Para GABRIELLI et al e TERRANOVA et al $(24,25) 92 \%$ das populaçóes pesquisadas atingiram a regulação do hábito intestinal incluindo aqueles com irregularidades esporádicas. LAUCKS et al(15) e MAZIER et al(18) encontraram, respectivamente, $100,00 \%$ e $93,00 \%$ dos clientes que se irrigavam, sempre ou usualmente livres de evacuaçoes nos intervalos das irrigações. WINTHER et 
al(29) falam de resultados satisfatórios obtidos por $90,00 \%$ de seus pacientes. $E$ DORAN e HARDCASTLE(6) e WILLIAMS e JOHNSTON(28) descrevem seus resultados através da média semanal de $6+-1$ movimentos intestinais para todos os clientes investigados.

Os dados publicados por esses autores parecem demonstrar que os resultados esperados para a irrigação, como método de controle do hábito intestinal em colostomizados, situam-se na ausência ou ocorrência esporádica de evacuações nos intervalos das irrigações, o que também constatamos para a maioria dos clientes estudados $(80,00 \%)$.

TABELA 2 - Respostas dos 26 clientes quanto às causas atribuídas às perdas fecais. São Paulo, 1988.

\begin{tabular}{l|c|c}
\hline Causas & N2 & $\%$ \\
\hline Alimentares & 16 & 45,71 \\
Técnicas & 5 & 14,29 \\
Psicologicas & 5 & 14,29 \\
Outras* & 4 & 11,43 \\
Desconhecidas & 4 & 11,43 \\
Não respondeu & 1 & 2,85 \\
& 35 & 100,00 \\
\hline Total & & \\
\hline
\end{tabular}

- "Uma vez por tomar Silidron" (1); "esforço excessivo" (1); " contato com produtos químicos (tintas)" ' (1); "quimioterapia" (1).

Conforme podemos observar, várias causas foram indicadas sendo mais freqüentes as alimentares $(45,71 \%)$ seguidas das técnicas e psicologicas, com igual percentual $(14,29 \%)$.

Para as causas alimentares, as respostas abrangeram desde aspectos quantitativos e qualitativos até o desconhecimento do alimento ingerido. Qualitativamente houve apenas referência a alimentos gordurosos.

Uma das grandes e comumente citadas vantagens da irrigação é a liberdade dietética do cliente, quando comparada a outros métodos de controle do hábito intestinal em colostomizados, principalmente o chamado natural $(6,7,9,13$, $21,23,25,28)$.

GOODE9 afirma que evacuações ocasionais entre as irrigações podem ser devidas a viroses gastrointestinais ou "indiscreções" dietéticas. GABRIELLI et al e TERRANOVA et al $(24,25)$ também imputaram os resultados obtidos em seus estudos, de continencia parcialmente satisfatória, às desordens alimentares ou enterites.

As respostas agrupadas como causas técnicas $(14,29 \%)$ foram: "irrigação 
mal feita", "temperatura da água" e irrigação incompleta "quando não saem todas as fezes".

Todo o treinamento do autocuidado do colostomizado e especialmente da irrigação da colostomia, deve englobar critérios que vão desde a seleção do cliente até a avaliação do treinamento e resultados obtidos, isto é, num processo de treinamento sistematizado como aquele por nós proposto e utilizado. Desta forma, julgamos ser possível minimizar as dificuldades que possam tornar-se motivo de insucesso da auto-irrigação como caracterizado nas causas técnicas.

Quanto às causas psicológicas, o estresse ("nervosismo", "preocupação", "contrariedade"), descrito aqui em 5 respostas $(14,29 \%)$, evidentemente interfere no desenvolvimento adequado de um método como a irrigaçáo, sendo mencionado como uma das causas da irregularidade do hábito intestinal pós-irrigaçăo.

JAO et al(13) e LAUCKS et al(15) identificaram, em seus trabalhos, assim como nós, que o estresse pessoal foi um fator influenciador no sucesso da irrigaçăo.

Outro fator que também interfere na motilidade do cólon e merece ser destacado é o uso de alguns medicamentos que podem afetar os resultados esperados com a irrigação. Apesar de 12 colostomizados empregarem medicações, em períodos variáveis, isso não foi levantado por eles como uma das causas para a existência de evacuaçōes entre as irrigações.

TABELA 3 - Número e percentagem de clientes segundo a presença e quantidade de gases nos intervalos das irrigaçōes. São Paulo, 1988.

\begin{tabular}{l|c|c}
\hline Gases & N2 & $\%$ \\
\hline Nåo & 11 & 27,50 \\
Sim: & 14 & 35,00 \\
- Menos que antes & 11 & 27,50 \\
- Igual a antes & 3 & 7,50 \\
- Mais que antes & 1 & 2,50 \\
Não respondeu & & 100,00 \\
\hline Total & 40 & \\
\hline
\end{tabular}

Cerca de $1 / 3$ da população ou $27,50 \%$ referem não apresentar gases depois que passaram a auto-irrigar-se. Ao adicionarmos a esse valor, o percentual daqueles que referem redução dos flatos $(35,00 \%)$, verificamos que um total de $62,50 \%$ dos clientes beneficiaram-se com o método, alcançando um resultado positivo esperado. Além disso, $27,50 \%$ dos clientes informam eliminação de gases igual ao período anterior.

Para o colostomizado, os gases e o odor são problemas importantes dentro do seu processo reabilitatório. Estes têm sido minimizados através do 
desenvolvimento de bolsas coletoras com filtros que permitem a sua eliminação, sem o cheiro desagradável. Além disso, existem também agentes desodorantes usados localmente ou ingeridos oralmente, tais como a clorofila, compostos de bismuto e carvão ativado(9).

A irrigação tem como uma das vantagens a redução dos gases e odor, uma vez que promove uma diminuição da flora bacteriana que participa no processo de formação gasosa.

MacLEOD(16) obteve redução de gases e odor diretamente relacionada com a freqüência da irrigação, identicamente às perdas fecais, ou seja, $20 \%, 40 \%$ e $40 \%$ dos clientes apresentavam gases e odor conforme irrigavam-se diariamente, em dias alternados ou a cada 3 dias, respectivamente. Os demais autores como CANTONE(4), DORAN e HARDCASTLE(6), GABRIELLI et al(7), LAUCKS et al(15) e TERRANOVA et al $(24,25)$ também encontraram resultados semelhantes, com a maioria de seus pacientes sem problemas de gases e odores apos a irrigação, em freqüências que variaram de $80 \%$ a $90 \%$.

TABELA 4 - Número e percentagem de clientes segundo o uso da bolsa coletora. São Paulo, 1988.

\begin{tabular}{l|c|c}
\hline Uso da bolsa coletora & N2 & $\%$ \\
\hline Situaçöes especificas* & 15 & 37,50 \\
Nunca usa & 13 & 32,50 \\
Sempre usa & 11 & 27,50 \\
Não respondeu & 1 & 2,50 \\
\hline Total & 40 & 100,00 \\
\hline
\end{tabular}

- Viajar (5); sair e viajar (4); sair, viajar e ir à piscina (1); sair, dormir, ir à piscina e viajar (1); sair e dormir (1); dormir (1); no dia da irrigação (1); quando irrigação insatisfatória (1).

Mais de 2,3 dos clientes $(70,00 \%)$, ou nunca usam a bolsa coletora $(32,50 \%)$ ou o fazem apenas em situações específicas $(37,50 \%)$.

Para as situações específicas verificamos que as mais indicadas pelos clientes foram: "viajar" (5) e "sair e viajar" (4).

Ao analisarmos cada situação isoladamente, excetuando-se a clientela que sempre utiliza a bolsa coletora $(27,50 \%)$, verificamos novamente que as mais citadas são: viajar (11 clientes) e sair (7 clientes). Cabe ressaltar, no entanto, que muitos não responderam ao item sobre o uso de bolsa para "ir à piscina ou praia" por não terem ainda experienciado a situação após a operação, por oportunidade ou opção.

A redução no uso áe bolsas coletoras com o emprego da irrigação tem sido atribuída como uma das grandes vantagens do método, tanto econômica como social e psicologicamente $(7,23,24,28)$.

Similarmente aos nossos resultados (32,50\%), WILLIAMS e JOHNS- 
TON(28) identificaram que cerca de $1 / 3$ dos pacientes deixaram de usar o coletor.

PIETRI et al(19) afirmam que pouco mais da metade dos pacientes continuam a usar o coletor ao sair de casa, por período prolongado ou durante as viagens.

Outros autores como GABRIELLI et al(7) e TERRANOVA et al(24, 25), verificaram que $1 / 4$ dos pacientes (25\%) utilizavam a bolsa para a resolução de problemas de gases e odor em viagens ou outras atividades sociais.

Diferentemente dos resultados apresentados por esses autores e por nós, para DORAN e HARDCASTLE(6) todos os clientes usavam a bolsa continuamente, apesar dos ótimos resultados conseguidos com a irrigação. LAUCKS et al(15) constataram que a maioria $(54,00 \%)$ dos colostomizados investigados sempre usavam bolsa.

Conforme podemos verificar, há controvérsias entre os relatos dos pesquisadores quanto ao uso de bolsas coletoras, porém se observa um aspecto em comum, ou seja, o da segurança, o que tem justificado a manutenção do emprego da bolsa pelos clientes mesmo que estes apresentem perdas fecais ausentes ou esporádicas, entre as irrigações.

TABELA 5 - Número e percentagem de clientes segundo o intervalo de tempo entre o treinamento da auto-irrigaçăo e abolição do uso da bolsa coletora em situações específicas. São Paulo, 1988.

\begin{tabular}{|c|c|c|c|c|c|c|c|c|c|c|}
\hline \multirow[t]{2}{*}{ Tempo } & \multicolumn{2}{|c|}{ Dormir } & \multicolumn{2}{|c|}{ Em casa } & \multicolumn{2}{|c|}{ Sair } & \multicolumn{2}{|c|}{ Viajar } & \multicolumn{2}{|c|}{ Piscina } \\
\hline & $\mathrm{n}^{\mathbf{\ell}}$ & $\%$ & $n^{2}$ & $\%$ & $\mathrm{n}^{\mathbf{2}}$ & $\%$ & $n^{2}$ & $\%$ & $\mathrm{n}^{2}$ & $\%$ \\
\hline Nunca aboliu* & 14 & 35,00 & 11 & 27,50 & 18 & 45,00 & 22 & 55,00 & 13 & 32,50 \\
\hline Imediatamente & & & & & & & & & & \\
\hline (ate 3 dias) & 9 & 22,50 & 8 & 20,00 & 8 & 20,00 & 6 & 15,00 & 7 & 17,50 \\
\hline 1 a 2 semanas & & & & & & & & & & \\
\hline (5 a 18 dias) & 6 & 15,00 & 6 & 15,00 & 3 & 7,50 & 2 & 5,00 & 2 & 5,00 \\
\hline 3 a 4 semanas & - & -. & 1 & 2,50 & - & - & 1 & 2,50 & 1 & 2,50 \\
\hline 8 semanas & 2 & 5,00 & 3 & 7,50 & 4 & 10,00 & 1 & 2,50 & 2 & 5,00 \\
\hline 12 semanas & 1 & 2,50 & 1 & 2,50 & 1 & 2,50 & 1 & 2,50 & 1 & 2,50 \\
\hline 32 semanas & 1 & 2,50 & 1 & 2,50 & - & - & - & - & - & -- \\
\hline Năo respondeu & 7 & 17,50 & 9 & 22,50 & 6 & 15,00 & 7 & 17,50 & 14 & $35,00 *$ \\
\hline Total & 40 & 100,00 & 40 & 100,00 & 40 & 100,00 & 40 & 100,00 & 40 & 100,00 \\
\hline
\end{tabular}

- Incluídos neste item todos os clientes que usam a bolsa todo o tempo

" Inclurdos neste item: "ainda năo testado" e "não freqüente".

Verificamos que a maior incidência de clientes que não aboliram o uso da bolsa o fizeram em situações fora de casa $(45,00 \%$ para "sair") e por tempo prolongado (55,00\% para "viajar"), como também já foi apresentado na Tabela 4.

Daqueles que aboliram o uso da bolsa, os periodos de tempo gastos para isto, após o treinamento da irrigação, variaram de imediatamente até 32 semanas 
(8 meses). Pelos dados da Tabela 5 podemos observar que a maior parte dos clientes que pararam de usar a bolsa o fizeram imediatamente apos o treinamento para as diversas situações: $22,50 \%$ para dormir; $20,00 \%$ em casa; $20,00 \%$ para sair de casa; $17,50 \%$ para ir à praia ou piscina e $15,00 \%$ para viajar. A seguir, o intervalo foi de 1 a 2 semanas para dormir e ficar em casa (15,00\%, em ambas situações).

Conforme verificamos, os valores decrescem para as atividades fora de casa em intervalos maiores, podendo significar que são situaçóes em que os clientes ainda utilizam a bolsa por segurança. A freqüência de respostas ausentes foi alta para todas as situações, principalmente nas de "freqüentar praia ou piscina".

\section{CONCLUSÕES}

O estudo sobre os resultados do emprego da auto-irrigação após um processo de treinamento sistematizado, alcançados por 40 clientes colostomizados no período de 1982 a 1988 , permitiu-nos concluir que tanto o método para o controle de hábito intestinal como o processo de treinamento empregado mostraram-se efetivos perante os seguintes resultados:

- o método de irrigação da colostomia adotado pela maioria dos clientes treinados reproduziu os itens básicos, preconizados no processo de treinamento;

- 37,50\% dos clientes não apresentaram perdas fecais nos intervalos das irriga-. ções e $42,50 \%$ as tinham esporadicamente, totalizando $80 \%$ com resultados esperados;

- 27,50\% dos clientes referiram não apresentar gases nos intervalos das irrigações e $35 \%$ os tinham em menor quantidade, totalizando $62,50 \%$ com resultados esperados;

- $32,50 \%$ dos clientes relataram nunca usar a bolsa coletora e $37,50 \%$, somente: o faziam em situações específicas, totalizando $70 \%$ ou $2 / 3$ da população com resultados esperados; $\mathrm{e}$

- as situaçōes específicas mais citadas pelos clientes para a manutenção do uso, da bolsa coletora foram aquelas de enfrentamento social e que demandavam períodos mais prolongados, como viajar (11 clientes) e sair ( 7 clientes).

SANTOS, V. L. C. G.; KOIZUMI, M.S. The results of colostomy self-irrigation after a systematic training process. Rev. Esc. Enf. USP, v. 26, n²3, p. - - , dec., 1992.

The present study comprises the results of the use of self-irrigation by 40 colostomized patients, trained by us through a process of systematized training. The effectiveness of the training process can be checked out considering that the most part of the patients have adopted it in its basic features, pointing out a few number of technical difficulties. As to the results of self-irrigation, as a method for controlling the intestinal habit, we can say that $37,50 \%$ of the population showed an absence of fecal leakages and 42,50\%, sporadic leakages between the irrigations; $27,50 \%$ and $35,00 \%$, with absence of gases in the intervals of time and partial use of the collecting pouch, respectively.

UNITERMS: Ostomy. Colostomy care. Irrigation 


\section{REFERENCIAS BIBLIOGRÁFICAS}

1. ABELLA, M. D. H. Aproximación a la ostomia. Rev. Enferm, v. 11, $n^{\circ} 118$, p. IV-XV, 1988.

2. AMDRUP, E.; CHRISTENSEN, P. Colostomy care: natural evacuation or irrigation? Am. J. Dig. Dis, v. $12, \mathrm{n}^{\circ} \mathrm{7}, \mathrm{p} .747-8,1967$.

3. BREGETZER, J. Irrigation des colostomies. Rev. Infirm., v. $34, n^{\otimes} 11$, p. 17-8, 1984.

4. CANTONE, G. La riabilitazione tardiva del paziente colostomizzato: la nostra esperienza. Minerva Med, v. 76, n 5, p. 143-7, 1985.

5. DONALDSON, D. R.; NORTHOVER, J. M. A. Continente colostomy devices. Surg Annu, v. 20, p. 145-58, 1988.

6. DORAN, J.; HARDCASTLE, J. D. A controlled trial of colostomy management by natural evacuation, irrigation and foam enema. Br. J. Surg, v. 68, no 10, p. 731-3, 1981.

7. GABRIELLI, F. et al. Risultati dell irrigazione periodica nella riabilitazione del colostomizzato. Minerva Chir.,v. 35, n²1, p. 1649-54, 1980.

8. GOLIGHER, J. C. Ileostomias e colostomias continentes. Rev. Bras. Colo-Proct, v. 6, n², p. 95-7, 1986.

9. GOODE, P.S. Colostomy irrigation. In: BROADWELL, D. C.; JACKSON, B. S. Principles of astomy care. Saint Louis, Mosby, 1982, cap. 26, p. 369-80.

10. HABR-GAMA, A. et al. Manual para astomizados irrigaçăo das colostomias. Săo Paulo, Nácleo de Assistencia a Ostomizados do Hospital das Clínicas da Faculdade de Medicina da USP, 1988. Mimeografado.

11. HABR-GAMA, A. et al. Utilizaçāo do oclusor magnético para colostomia continente. Rev. Assoc. Med Bras., v. $26, n^{2} 12$, p. $397-400,1980$.

12. HAMPTON, B. Colostomy care. Cancer Bull, v. 33, $n^{9} 1$, p. 8-9, 1981.

13. JAO, S. W. et al. Irrigation management of sigmoid colostomy. Arch. Surg, v. 120, $\mathrm{n}^{9} 8$, p. 916-7, 1985.

14. JULIEN, J. et al. Table ronde: l'irrigation colique. Soins Chir., v. 48, p. 37-46, 1985.

15. LAUCKS, S. S. et al. An assessment of colostomy irrigation. Dis. Colon Rectum, v. 31, n\& 4, p. 279-82, 1988.

16. MacLEOD, J. H. Colostomy irrigation: a transatlantic controversy. Dis. Colon Rectum, v. 15, n 5, p. $357-60,1972$.

17. MAHONEY, J. M. Guide to astomy nursing care. Boston, Little Brown, 1976.

18. MAZIER, W. P. et al. Effective colostomy irrigation. Sur. Gynecol. Obstet, v. 142, n96, p. 905-9, 1976.

19. PIETRI, P. et al. Riabilitazione dell enterostomizzato. Chir. Triven, v. 18, n 3, p. 421-38, 1978.

20. REBOA, G. et al. Biofeedback training to obtain continence in permanent colostomy: experience of two centers. Dis. Colon Rectum., v. 28, n² 6, p. 419-21, 1985.

21. SANTOS, V. L. C. de G. Relato de experiencia no treinamento da irrigação intestinal em uma paciente colostomizada. Rev. Paul. Enf., v. 5, no 2, p. 73-6, 1985.

22. SCHELLERER, W. Erlangen continent magnetic colostomy (ECMC). IN: TODD, I. P. Intestinal stomas. London, William Heinemann, 1978, cap. 4, p. 36-40.

23. SEARGEANT, P. W. Colostomy management by the irrigation technique: review of 165 cases. Br. Med. J., v. 2, no 5.504, p. 25-6, 1966. 
24. TERRANOVA, O. et al. Irrigare o non irrigare il colostomizzato? Chir. Triven, v. 17, no 3, p. 270-80, 1977.

25. I_ Irrigation versus natural evacuation of left colostomy: a comparative study of $\mathbf{3 4 0}$ patients. Dis. Colon Rectum, v. 22, n² 1, p. 31-4, 1979.

26. TORRES, R. A.; GONZALEZ, M. A. Colostomia continente con neoesfinter. Rev. Argent. Cirug, v. $47, n^{2} 1 / 2$, p. $1-5,1984$.

27. VALENTI, M. T.; LAGUNA, M. V. Evacuación controlada en pacientes ostomizados. Rev. Enferm, v. $9, \mathrm{n} \div 100$, p. 109-14, 1980.

28. WILLIANS, N. S.; JOHNSTON, D. Prospective controlled trial comparing colostomy irrigation with "spontaneous action" method. Br. Med. J., v. 281, n6.233, p. 107-9, 1980.

29. WHINTER, A. P. et al. Function of a colostomy outpatient clinic with reference to teaching colon irrigation. Ugesks Laeger, v. 149, n 50, p. 3.400-2, 1987. 